Original Article

\title{
Effectiveness Magnesium Sulphate Crystal Fomentation Vs Paste Application for Phlebitis among Children Receiving Peripheral Infusion who are Admitted at Selected Hospital at Mangalore
}

\author{
Brincy Loyolla D'souza' \& Shivakumar ${ }^{2}$ \\ ${ }^{1}$ Lecturer, Department of Child Health Nursing, Father Muller college of Nursing, M angalore \\ 'Lecturer, Department of Child Health Nursing, Sahyadri Institute of Health Sciences, M angalore \\ Correspondence \\ Brincy Loyolla D'Souza \\ Lecturer, Department Of Child Health Nursing, Father Muller college of Nursing, Mangalore, Karnataka, India \\ Mobile : +91 9886394706 E-mail : brincy85@gmail.com
}

\begin{abstract}
Background : Peripheral cannulation is one of the commonly used procedures in children, as they have to undergo many infusions for the administration of medications. The nurse is responsible for maintaining and monitoring IV infusion site and promptly detecting any complication like phlebitis, infiltration, air embolism, infection and fluid overload. In children phlebitis is the most commonly seen due to their fragile veins and therefore special attention should be given to minimize the occurrence of phlebitis and also to treat it effectively.
\end{abstract}

Objective : to determine the effectiveness magnesium sulphate crystal fomentation vs glycerin magnesium sulphate paste application for phlebitis among children receiving peripheral infusion.

Setting \& Design : Regional Advance Pediatric Care Center (RAPCC), M angalore.

M aterial and M ethods : Quasi experimental design phlebitis measurement chart and observation checklist for erythema.

Result and Conclusion: the mean pre-treatment scores of phlebitis were significantly reduced after the treatment with magnesium sulphate fomentation and with glycerin magnesium sulphate paste application. The mean post treatment score of phlebitis at $p \varangle 0.05$. Glycerin magnesium sulphate paste was effective in reducing swelling and induration when compared to magnesium sulphate crystal fomentation.

Keywords : Phlebitis; peripheral infusion; glycerin magsnesium sulphate paste; magnesium sulphate crystals.

\section{Introduction}

Intravenous therapy is increasing especially in children and it has also manifested some minor side effects like pain, trauma, swelling, temporary joint immobility. The study estimated that over $80 \%$ of all children hospitalised receive IV therapy ${ }^{1}$. These can lead to life threatening conditions like thrombosis, embolism, and variety of infections and so on if proper care is not considered promptly. Phlebitis is one of the common side Access this article online Quick Response Code

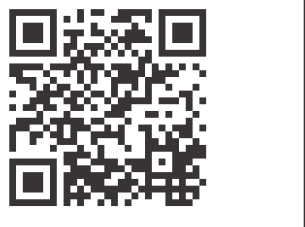

subcutaneous tissues due to the dislodgement or malfunctioning of the cannula. Magnesium sulphate can be very useful in preventing and treating phlebitis'. Thus the researcher would want to find out the better and cost effective method of reducing phlebitis using the Magnesium preparation, when compared with the traditionally used magnesium Paste.

\section{Objectives of the studywere to:}

- Determine the effectiveness of magnesium sulphate crystal fomentation on phlebitis.

- Determine the effectiveness of glycerin magnesium sulphate paste application on phlebitis.

- compare the effectiveness of both intervention on phlebitis

Purpose of the study was to find the effect of magnesium product in reducing phlebitis 


\section{Materials and methods}

A quasi-experimental approach with pre-test post-test design was used for the study. The study sample consisted of 60 children with phlebitis, where 30 children were placed in group I, treated with magnesium sulphate crystal fomentation and 30 children were placed in group II, treated with glycerin magnesium sulphate paste application. Purposive sampling technique was used to select the children. The study was conducted at Regional Advance Pediatric Care Centre (RAPCC), M angalore. The tool was developed after intensive review of literature, consultation and discussion with experts and also with the personal experience of the researcher. Tool was validated by 13 experts in the field of Pediatrics and Pediatric nursing. The final tool consisted of three parts. Part 1: Demographic Proforma Part 2: Phlebitis Measurement Chart Part 3: Observation Checklist for Erythema. The assessment of phlebitis was done prior to the application of magnesium sulphate crystal fomentation and glycerin sulphate paste application by using phlebitis measurement chart and observation checklist for erythema. Post treatment assessment was conducted on the 3rd day using the same phlebitis measurement chart and observation checklist for erythema. A pre-treatment assessment was conducted to assess the phlebitis by using phlebitis measurement chart and observation checklist for erythema, after which the interventions were administered to both groups respectively for three days 3 times a day $(6 a m+2 p m+10$ $\mathrm{pm})$. A post treatment assessment was conducted on the third day using the same tool. Ethical clearance was obtained from concerned institution. The investigator conducted the pilot study on 10 children, five in treatment I and five in treatment II who satisfied the inclusion and exclusion criteria. The main study was done on 60 children 30 in treatment I and 30 in treatment II. Informed consent was taken from subjects and confidentiality was assured. The Inclusion criteria was: Children between the age group of 1-12 years receiving peripheral infusion including chemotherapeutic infusions.

\section{Statistical Methods}

The results were analysed using descriptive statistics like mean, standard deviation and inferential statistics like ' $\mathrm{t}$ ' test. Pre-treatment and post treatment of both the treatment groups were record and compiled for analysis.

\section{Results}

Table 1: Demographic Data

\begin{tabular}{|llcc|}
\hline $\begin{array}{l}\text { Demographic } \\
\text { data }\end{array}$ & Items & Frequency & Percentage \\
\hline Agein years & $1-4$ & 12 & 20 \\
& $5-8$ & 21 & 35 \\
& $9-12$ & 27 & 45 \\
\hline Gender & Male & 32 & 53.3 \\
& Female & 28 & 46.7 \\
\hline Site of & Doral palm & 32 & 53.33 \\
intravenous & Ventral aspect of fore arm & 13 & 21.67 \\
Insertion & Wrist and antecubital fossa & 12 & 20 \\
& Dorsal vein of leg & 8 & 5 \\
\hline Types of fluids & Hydrational fluid & 43 & 71.67 \\
& Inotropic infusion & 0 & 0 \\
& Vasodilator infusion & 6 & 3.33 \\
& Antibiotic & 2 & 10 \\
& Chemotherapeutic druginfusion & 9 & 15 \\
\hline duration of & 0-30 & 5 & 8.33 \\
infusion & $31-60$ & 41 & 68.33 \\
& 61-90 & 13 & 21.67 \\
& $>91$ & 1 & 1.67 \\
\hline
\end{tabular}


Table 2 : Effectiveness of magnesium sulphate crystal fomentation

$(\mathrm{N}=30)$

\begin{tabular}{|l|c|c|c|c|c|c|c|c|}
\hline \multirow{2}{*}{ Parameters } & \multicolumn{2}{|c|}{ Pre-treatment } & \multicolumn{2}{c|}{ Post-Treatment } & \multicolumn{2}{c|}{ Paired differences } & \multirow{2}{*}{ 't' value } & \multirow{2}{*}{$p<0.05$} \\
\cline { 2 - 7 } & Mean & SD & M ean & SD & M ean & SD & & \\
\hline Swelling & 33.05 & 22.02 & 5.13 & 4.31 & 27.92 & 19.31 & $7.92^{*}$ & 0.000 \\
\hline Induration & 17.26 & 10.70 & 3.03 & 2.76 & 14.24 & 9.57 & $8.15^{*}$ & 0.003 \\
\hline Erythema & 2.07 & 0.64 & 0.73 & 0.63 & 1.33 & 0.55 & $13.36^{*}$ & 0.000 \\
\hline
\end{tabular}

Table 3 : Effectiveness of application of glycerin magnesium sulphate paste

$(\mathrm{N}=30)$

\begin{tabular}{|l|c|c|c|c|c|c|c|c|}
\hline \multirow{2}{*}{ Parameters } & \multicolumn{2}{|c|}{ Pre-treatment } & \multicolumn{2}{c|}{ Post-Treatment } & \multicolumn{2}{c|}{ Paired differences } & \multirow{2}{*}{ 't' value } & \multirow{2}{*}{$p<0.05$} \\
\cline { 2 - 7 } & Mean & SD & M ean & SD & M ean & SD & & \\
\hline Swelling & 29.09 & 22.37 & 2.47 & 1.99 & 26.62 & 22.01 & $6.62^{*}$ & 0.237 \\
\hline Induration & 11.36 & 9.11 & 1.36 & 1.34 & 10.01 & 8.89 & $6.16^{*}$ & 0.208 \\
\hline Erythema & 2.0 & .69 & 043 & 0.56 & 1.57 & 0.63 & $13.71^{*}$ & 0.003 \\
\hline
\end{tabular}

Table 4: Comparison of the effectiveness of the two modalities of treatment in the reduction of phlebitis after the application of interventions

$(\mathrm{N}=30+30=60)$

\begin{tabular}{|c|c|c|c|c|c|c|c|c|}
\hline \multirow[t]{2}{*}{$\begin{array}{l}\text { Treatment } \\
\text { groups }\end{array}$} & \multicolumn{2}{|c|}{$\begin{array}{l}\text { magnesium sulphate } \\
\text { crystal fomentation }\end{array}$} & \multicolumn{2}{|c|}{$\begin{array}{l}\text { glycerin magnesium } \\
\text { sulphate paste } \\
\text { application }\end{array}$} & \multicolumn{2}{|c|}{ Paired differences } & \multirow[t]{2}{*}{ 't' value } & \multirow[t]{2}{*}{$p<0.05$} \\
\hline & Mean & SD & Mean & SD & Mean & SD & & \\
\hline \multicolumn{9}{|c|}{ Pre - treatment } \\
\hline Swelling & 33.05 & 22.02 & 29.09 & 22.37 & 3.96 & 0.349 & 0.692 & 0.492 \\
\hline Induration & 17.27 & 10.70 & 11.37 & 9.11 & 5.90 & 1.59 & $2.300^{*}$ & 0.025 \\
\hline Erythema & 2.07 & 0.64 & 2.0 & 0.69 & 0.067 & 0.055 & 0.387 & 0.700 \\
\hline \multicolumn{9}{|c|}{ Post - Treatment } \\
\hline Swelling & 5.1283 & 4.32 & 2.47 & 1.99 & 2.66 & 2.33 & $3.061 *$ & 0.003 \\
\hline Induration & 3.029 & 2.76 & 1.36 & 1.35 & 1.67 & 1.413 & $2.974 *$ & 0.004 \\
\hline Eythema & 0.73 & 0.64 & 0.43 & 0.57 & 0.3 & 0.071 & 1.920 & 0.060 \\
\hline
\end{tabular}

\section{Discussion}

\section{Effectiveness of magnesium sulphate crystal fomentation}

These findings were supported by a study done for managing local tissue damage caused by extravasation of pharmorubicin with hydropathic compress by Xueming J, Yun L in China in 2005. 50\% magnesium sulphate solution and $2 \%$ lidocaine and hexadecadrol therapy were used. Here $50 \%$ magnesium sulphate solution was found to be effective in reducing phlebitis ${ }^{5}$.

\section{Effectiveness of Glycerin Magnesium Sulphate Paste Application}

A study was done by Biswas $D$ in her dissertation to compare the effect of four selected nursing interventions on patients with phlebitis related to peripheral intravenous infusion in Kolkata, West Bengal in 2005 like ichthammol belladonna dressing (treatment I), glycerin magnesium sulphate dressing (treatment II), ichthammol belladonna dressing along with hot fomentation (treatment III) and glycerin magnesium sulphate dressing (IV). It was found that ichthammol belladonna dressing along with hot fomentation was more effective among the four modalities, but it also said that glycerin magnesium sulphate was being used effectively in the treatment of phlebitis ${ }^{4}$

\section{Comparision of Two Modalities of Treatment in the Reduction of Phlebitisin Children.}

These findings are supported by the study done by Huo G, Ying-Jia L, Hui-Juan $M$ on the efficacy of glycerin magnesium sulfate emulsion on the treatment of peripheral phlebitis in 2006. The treatment with glycerin magnesium sulfate emulsion was found to take less time $2.16 \& 0.39$ days compared to control group (treated with 
$50 \%$ magnesium sulphate solution) which took $5.17 \& 1.15$ days $^{6}$. The results of another study done by Lakhani AK, M erchant RJ, Khowaja K in 2006 using glycerin magnesium sulphate paste (treatment I) and magnesium sulphate salt solution (treatment II) also support the present study. It was found that third day post application score of treatment I were 0.7071 and that of treatment II was 1.7571. This clearly indicates that glycerin magnesium sulphate paste was effective in reducing phlebitis?.

\section{Recommendations}

M ore studies could be conducted on the large sample and using other form of magnesium products. A study could be conducted to determine the effectiveness of either of the treatments in reducing pain or palpable cord lengths. A study could be conducted to determine the effectiveness of other cost effective modalities like ice application in treatment of phlebitis.

\section{Conclusions}

Thus glycerin magnesium sulphate paste application was found to be very effective when compared with magnesium sulphate fomentation in reducing swelling and in duration. This study concludes that the magnesium products are very effective in reducing phlebitis and other infusion related complication. It is a very cost effective method with minimal resources, requires minimal training too, and very easy to use with little or no complications. The study was conducted only on a small sample and limited participants for a very short period thus generalisation is not possible.

\section{Acknowledgement}

- Regional Advanced Paediatric Care Center (RAPCC) for permitting to conduct the study

- Principal \& teaching faculty of Sahyadri College of Nursing, especially Department of Child Health Nursing for material help, general support.

- Participants of the study for their whole hearted participation

\section{References}

1. Campbell H. IV related phlebitis. Complications and length of hospital stay 1.British Journal of Nursing 1998; 7 (21): 1767-86.

2. Lakhani AK, Merchant RJ, Khowaja K. Translating research into practice. Intravenous (I/V) related phlebitis 2006; 7(22).

3. At glance IV tips. Phlebitis- the sequeal infusion nurse. April; 2010.

4. Biswas D. Dissertation to compare the effect of four selected nursing interventions on patients with phlebitis related to peripheral intravenous infusion in selected hospital of Kolkata. West Bengal; 2005.

5. Xueming J, Yun L. Correlative study for managing local tissue damage caused by extravasation of pharmorubicin. Journal of Nurses Training 2005; (1): 329.

6. Huo G, Ying-Jia L, Hui-Juan M. Efficacy observation of glycerin magnesium sulfate emulsion on the treatment of peripheral phlebitis. Journal of Infusion Nursing 2006; 26: 49-54.

7. Lakhani AK, Merchant RJ, Khowaja K. translating research into practice. Intravenous (I/V) related phlebitis: incidence and associated risk factors. The $17^{\text {th }}$ international nursing research congress focusing on evidence-based practice; 2006. 